\title{
Communication
}

\section{A New Geldanamycin Analogue from Streptomyces hygroscopicus}

\section{Hao Zhang ${ }^{1}$, Guang-Zhi Sun ${ }^{2}$, Xiang Li ${ }^{3}$, Hong-Yu Pan ${ }^{3, *}$ and Yan-Sheng Zhang ${ }^{4, *}$}

1 School of Resources and Environment, Jilin Agricultural University, Changchun, 130118, China; E-Mail: haozhang100@163.com (H.Z.)

2 Institute of Agricultural Modernization, Jilin Agricultural University, Changchun, 130118, China; E-Mail: gzsun1967@yahoo.com (G.-Z.S.)

3 College of Plant Science, Jilin University, Changchun, 130062, China; E-Mail: drxiang@hotmail.com (X.L.)

4 Wuhan Botanical Garden, Chinese Academy of Sciences, Wuhan, 430074, China;

* Authors to whom correspondence should be addressed; E-Mails: zhangys@wbgcas.cn (Y.-S.Z.); panhongyu@jlu.edu.cn (H-Y.P.).

Received: 5 January 2010; in revised form: 10 February 2010 / Accepted: 2 March 2010 / Published: 3 March 2010

Abstract: A new geldanamycin analogue was isolated from Streptomyces hygroscopicus A070101. The structure was elucidated as 11-methoxy-17-formyl-17-demethoxy-18-O-21$O$-dihydrogeldanamycin (1) on the basis of extensive 1D and 2D NMR as well as HRESIMS spectroscopic data analysis. Compound 1 showed considerable cytotoxicity (SRB) against human cancer cell lines (breast cancer MCF-7, skin melanoma SK-MEL-2 and lung carcinoma COR-L23).

Keywords: Streptomyces hygroscopicus; 11-methoxy-17-formyl-17-demethoxy-18-O-21$O$-dihydrogeldanamycin; geldanamycin 


\section{Introduction}

Steroid hormone receptors are generally intracellular receptors and initiate signal transduction for steroid which lead to changes in gene expression over a time period ranging from hours to days [1]. During the translation, steroid receptors are assembled into a multi-protein complex containing hsp90 (one of the most abundant proteins expressed in cells) [2], p23, an immunophilin, and often some hsp70 [3]. Geldanamycin analogues were found to bind to hsp90 and disrupt its function, impedes dexamethasone-dependent trafficking of the glucocorticoid receptor from the cytoplasm to the nucleus, led many of them are protooncogenic and play a prominent role in cancer [4]. For example, geldanamycin and its analog 17-AAG showed significant cytotoxicity against human cancer cell line $\mathrm{SKBr} 3$ ( $\mathrm{IC}_{50}=41$ and $33 \mathrm{nM}$, respectively) [5]. During our continued work on bioactive bacteria and fungi, a Streptomyces hygroscopicus strain was isolated from the soil of Chang-Bai Mountain. A new geldanamycin analogue was isolated from a $20 \mathrm{~L}$ fermentation of this strain. Its structure was elucidated as 11-methoxy-17-formyl-17-demethoxy-18-O-21-O-dihydrogeldanamycin (1, Figure 1) on the basis of extensive 1D and 2D NMR as well as HRESI-MS spectroscopic data analysis. Compound 1 was tested with five-day in vitro SRB cytotoxicity against human tumors cell lines and showed considerable cytotoxicity against human cancer cell lines (breast cancer MCF-7, skin melanoma SKMEL-2 and lung carcinoma COR-L23).

Figure 1. Structure of 11-methoxy-17-formyl-17-demethoxy-18-O-21-O-dihydrogeldanamycin (1).

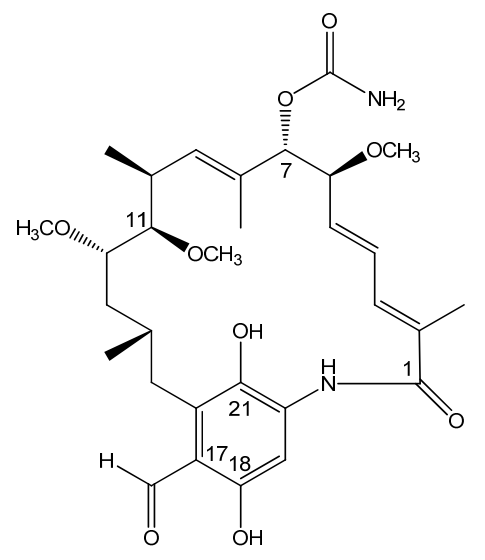

\section{Results and Discussion}

\section{Characterization of compound $\mathbf{1}$}

The molecular formula of compound 1 was determined as $\mathrm{C}_{30} \mathrm{H}_{42} \mathrm{~N}_{2} \mathrm{O}_{9}$ on the basis of its HR-ESIMS ( $m / z$ 575.2981 $[\mathrm{M}+\mathrm{H}]^{+}$, calcd. 575.2969) and NMR data (Table 1). Analysis of the ${ }^{13} \mathrm{C}-\mathrm{NMR}$ spectrum and DEPT experiments, allowed the identification of seven methyl groups, two methylenes, eleven methines and ten quaternary carbons. Analysis of the ${ }^{1} \mathrm{H}-{ }^{1} \mathrm{H}$ COSY (Figure 2) and HMQC spectra suggested the presence of two ${ }^{1} \mathrm{H}-{ }^{1} \mathrm{H}$ spin systems: $\mathrm{H}_{3}-\mathrm{H}_{4}-\mathrm{H}_{5}-\mathrm{H}_{6}-\mathrm{H}_{7}, \mathrm{H}_{9}-\mathrm{H}_{10}-\mathrm{H}_{11}-\mathrm{H}_{12}-\mathrm{H}_{13}-\mathrm{H}_{14}-$ $\mathrm{H}_{15}$. The chemical shifts of the protons and carbons (Table 1) were similar to those of the previously reported compound, 17-formyl-17-demethoxy-18-O-21-O-dihydrogeldanamycin, a geldanamycin 
analogue isolated from recombinant $S$. hygroscopicus strain [6]. The main differences between the two metabolites concerned a newly appeared methoxyl group $\left[\delta_{\mathrm{C}} 57.2, \delta_{\mathrm{H}} 3.37(s)\right]$ in compound $\mathbf{1}$. The location of the methoxyl group was established taking into account the correlation observed between $11-\mathrm{OCH}_{3}(\delta 3.37)$ and $\mathrm{C}-11(\delta 156.8)$ in the HMBC experiment of 1 (Figure 2$)$. The coupling constant between the H5 and H6 (11.2 Hz), H9 and H10 (8.8 Hz), were similar to the literature values $10.4 \mathrm{~Hz}$ and $9.6 \mathrm{~Hz}$ [6], respectively, led to determine the relative stereochemistry same as reported compound KOSN 1645.

Table 1. The NMR data of compound 1.

\begin{tabular}{|c|c|c|c|c|c|}
\hline \multirow{2}{*}{ No. } & \multicolumn{3}{|c|}{ Compound $\mathbf{1}$} & \multicolumn{2}{|c|}{ KOSN $1645^{b}$} \\
\hline & ${ }^{1} \mathrm{H}-\mathrm{NMR}$ & ${ }^{13} \mathrm{C}-\mathrm{NMR}$ & DEPT & ${ }^{1} \mathrm{H}-\mathrm{NMR}$ & ${ }^{13} \mathrm{C}-\mathrm{NMR}$ \\
\hline 1 & - & 169.1 & $\mathrm{C}$ & - & 167.3 \\
\hline 2 & - & 135.2 & $\mathrm{C}$ & - & 136.7 \\
\hline 3 & $7.01(d, J=12.0)$ & 124.3 & $\mathrm{CH}$ & $6.85(d, J=11.2)$ & 124.7 \\
\hline 4 & $6.22(t, J=12.0)$ & 128.6 & $\mathrm{CH}$ & $6.35(t, J=11.2)$ & 127.1 \\
\hline 5 & $5.24(t, J=11.2)$ & 133.3 & $\mathrm{CH}$ & $5.71(t, J=10.4)$ & 132.9 \\
\hline 6 & $3.99(d, J=11.2)$ & 79.6 & $\mathrm{CH}$ & $4.31(d, J=10.4)$ & 80.9 \\
\hline 7 & $4.83(s)$ & 80.7 & $\mathrm{CH}$ & $4.96(s)$ & 82.8 \\
\hline 8 & - & 132.6 & $\mathrm{C}$ & - & 133.4 \\
\hline 9 & $5.47(d, J=8.8)$ & 133.1 & $\mathrm{CH}$ & $5.94(d, J=9.6)$ & 133.4 \\
\hline 10 & $2.51(\mathrm{~m})$ & 32.1 & $\mathrm{C}$ & $2.81(q n, J=7.6)$ & 32.3 \\
\hline 11 & $3.73(\mathrm{~m})$ & 72.9 & $\mathrm{CH}$ & $3.63(\mathrm{~m})$ & 74.7 \\
\hline 12 & $3.57(\mathrm{~m})$ & 79.3 & $\mathrm{CH}$ & $3.5(m)$ & 80.3 \\
\hline 13 & $1.86(\mathrm{~m})$ & 33.7 & $\mathrm{CH}_{2}$ & $1.88(b r)$ & 35.4 \\
\hline 14 & $1.83(\mathrm{~m})$ & 29.3 & $\mathrm{CH}$ & $1.6-1.8(o v)$ & 29.2 \\
\hline 15 & $2.58(\mathrm{~m})$ & 33.1 & $\mathrm{CH}_{2}$ & $2.72(b r)$ & 33.4 \\
\hline 16 & - & 126.9 & $\mathrm{C}$ & - & 127.3 \\
\hline 17 & - & 114.2 & $\mathrm{C}$ & - & 113.1 \\
\hline 18 & - & 159.3 & $\mathrm{C}$ & - & 159.4 \\
\hline 19 & $7.71(s)$ & 105.6 & $\mathrm{CH}$ & $7.93(s)$ & 104.7 \\
\hline 20 & - & 132.3 & $\mathrm{C}$ & - & 135.6 \\
\hline 21 & - & 140.6 & $\mathrm{C}$ & - & 136.4 \\
\hline 2-Me & $1.65(s)$ & 11.8 & $\mathrm{CH}_{3}$ & $1.59(s)$ & 12.4 \\
\hline 8-Me & $1.68(s)$ & 11.3 & $\mathrm{CH}_{3}$ & $1.79(s)$ & 12.6 \\
\hline $10-\mathrm{Me}$ & $0.91(d, J=7.2)$ & 10.9 & $\mathrm{CH}_{3}$ & $0.93(d, J=7.2)$ & 12.1 \\
\hline 14-Me & $0.97(d, J=8.8)$ & 23.1 & $\mathrm{CH}_{3}$ & $0.95(d, J=8.8)$ & 22.4 \\
\hline 6-OMe & $3.29(s)$ & 55.9 & $\mathrm{CH}_{3}$ & $3.36(s)$ & 56.9 \\
\hline 11-OMe & $3.37(s)$ & 57.2 & $\mathrm{CH}_{3}$ & - & - \\
\hline 12-OMe & $3.31(s)$ & 57.7 & $\mathrm{CH}_{3}$ & $3.22(d)$ & 57.1 \\
\hline 17-CHO & $9.81(s)$ & 191.0 & $\mathrm{C}$ & $10.09(s)$ & 193.2 \\
\hline 7-carbamate & $8.50(s)$ & 155.5 & $\mathrm{C}$ & $8.73(s)$ & 156.5 \\
\hline
\end{tabular}

${ }^{\mathrm{a}}$ Compound 1 was measured in DMSO- $d 6$ and chemical shifts are expressed in ppm; ${ }^{\mathrm{b}} \mathrm{H}$ and ${ }^{13} \mathrm{C}-\mathrm{NMR}$. data (in $\mathrm{CDCl}_{3}$ ) of KOSN 1645 were extracted from [6]. 
Figure 2. COSY and HMBC of compound 1.

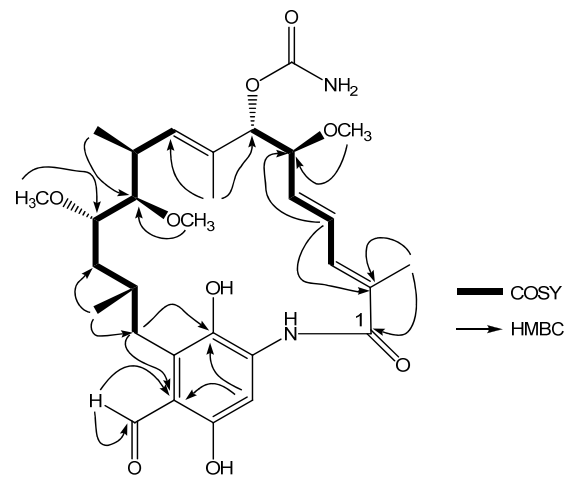

The biosyntheses of geldanamycin analogues were reported to be involved in the assembly of 3-amino-5-hydroxybenzoic acid (AHBA) as a starter unit, following elongation with the acyl-Coenzyme A substrates malonyl-CoA, methylmalonyl-CoA, and 2-methoxymalonyl-ACP, the polyketide intermediate undergoes intra-molecular lactamization by gdmF to form progeldanamycin [5,7] (Figure 3). The compound 1 isolated in this study and previously reported herbimycin A [6], proposed that an $O$-methylation step exist after the formation of polyketide backbone which may lead to identify a new $O$-methyltransferase. To prove this hypothesis, mutant lines could be established for screening of this $11-O$-methyltransferase.

Figure 3. Speculated biosynthetic pathway of compound 1.

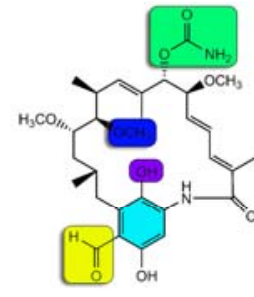

Compound 1

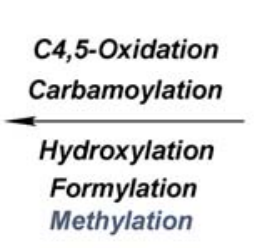

Methylation

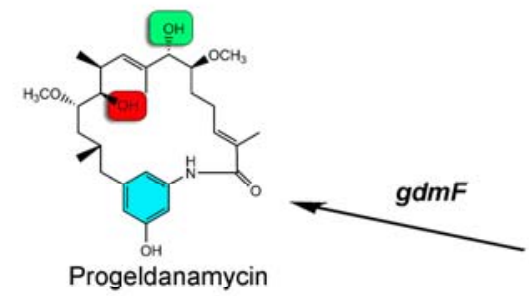

Progeldanamycin
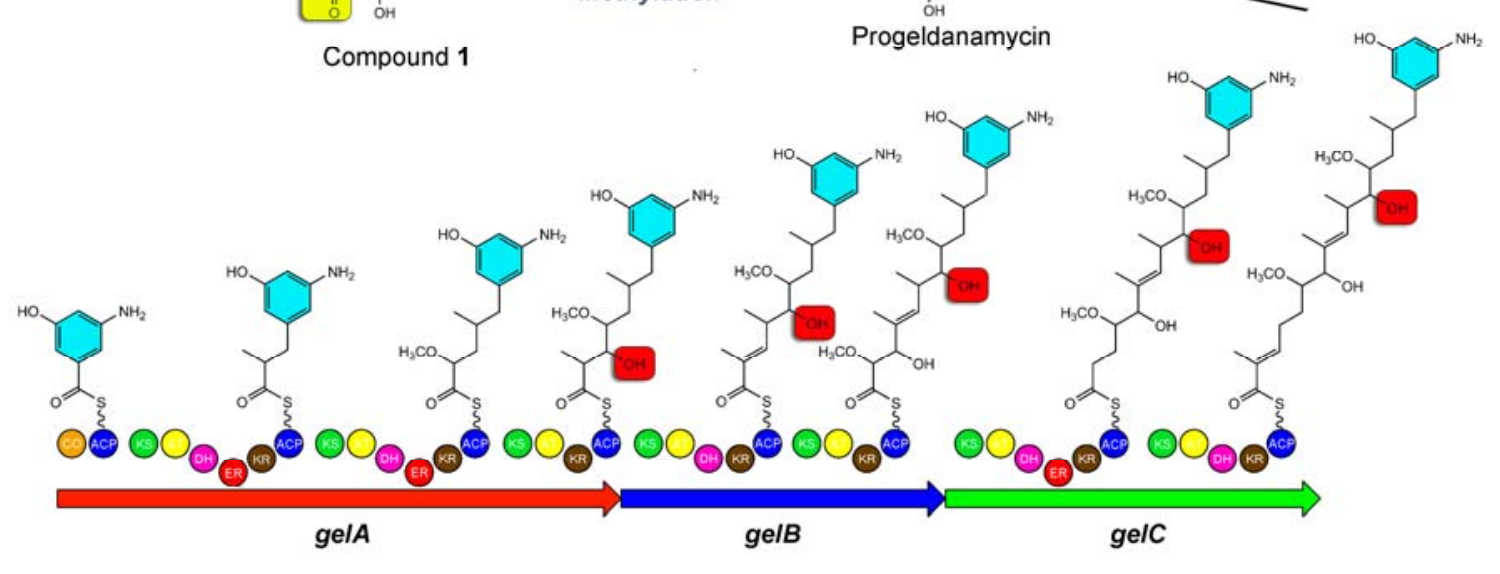

Bioactivity results

Compound 1 was tested in anti-tumor bioassays and showed significant cytotoxicity (SRB) against several human cancer cell lines: breast cancer MCF-7 $\left(\mathrm{IC}_{50}=142 \mathrm{nM}\right)$, skin melanoma SK-MEL-2 $\left(\mathrm{IC}_{50}=496 \mathrm{nM}\right)$ and lung carcinoma COR-L23 $\left(\mathrm{IC}_{50}=278 \mathrm{nM}\right)$. 


\section{Conclusions}

In summary, we have isolated a new geldanamycin analogue 11-methoxy-17-formyl-17demethoxy-18-O-21-O-dihydrogeldanamycin (1) from a $20 \mathrm{~L}$ of Streptomyces hygroscopicus A070101 fermentation broth. Compound 1 showed considerable cytotoxicity against human cancer cell lines (breast cancer MCF-7, skin melanoma SK-MEL-2 and lung carcinoma COR-L23).

\section{Experimental}

\section{General}

The ${ }^{1} \mathrm{H}$ - and ${ }^{13} \mathrm{C}$-NMR spectra were measured on a Bruker Avance DRX 500 NMR spectrometer in DMSO- $d_{6}$, using TMS as an internal standard. Chemical shifts $(\delta)$ are expressed in parts per million (ppm), with the coupling constants $(J)$ reported in Hertz $(\mathrm{Hz})$. The HR-ESI mass spectrum was obtained from a MDS SCIEX API QSTAR-MS instrument. TLC was performed with silica gel plates (Macherey -Nagel, SilG / UV254, 0.20mm); Semi-preparative HPLC was carried out with Agilent 1100 on a Zorbax $\mathrm{C}_{18}$ column ( $250 \times 10 \mathrm{~mm}$, Phenomenex, Torrance, CA), UV absorption data $\left(\lambda_{280}\right)$ were analyzed with Agilent Chemstation Ver 8.01. All solvents used in this study were HPLC grade, purchased from the Chinese Chemical Group, Beijing, China.

\section{Bacterial strain and growth conditions}

Bacterial strain A070101 was obtained from Chang-Bai Mountain soil during a systematic screening of ginsenoside-glucosidase-produced bacteria [10] and was identified as Streptomyces hygroscopicus by professor Zhao-Yang He (Jilin Agricultural University). Geldanamycin production medium (GPM), consist of sucrose (50 g/liter), peptone ( $2 \mathrm{~g} /$ liter), tryptone ( $2 \mathrm{~g} /$ liter $)$, yeast-extract ( $2 \mathrm{~g} /$ liter), Gerber's oatmeal (5 g/liter), and Brer Rabbit molasses $(10 \mathrm{ml} / \mathrm{liter})(\mathrm{pH}=7.0)$, was used to produce geldanamycin homologues [11]. The fermentation was carried in fifty $1 \mathrm{~L}$ flasks at $28{ }^{\circ} \mathrm{C}$ for 7 days.

\section{Extraction and isolation of compound $\mathbf{1}$}

The lyophilized culture broth was extracted with $80 \% \mathrm{EtOH}$ at room temperature. The extract was concentrated under reduced pressure to give the pale brown residue $(625 \mathrm{mg})$ that was fractionated by reverse phase (C-8) chromatography using $\mathrm{H}_{2} \mathrm{O}$, aqueous $\mathrm{MeOH}(30 \%, 60 \%, 90 \%)$ and $\mathrm{MeOH}$ to give four fractions: the $90 \% \mathrm{MeOH}$ fraction was further fractionated on a Sephadex $\mathrm{LH}-20$ column $\left(\mathrm{CHCl}_{3}\right.$ : $\mathrm{MeOH}=1: 1)$ and then purify by semi-preparative HPLC to yield compound 1 (3.6 mg, $0.18 \mathrm{mg} / \mathrm{L}$, whereas yield of geldanamycin was reported as $\sim 10 \mathrm{mg} /$ liter) [6].

\section{In vitro cytotoxicity assays}

Five-day in vitro SRB cytotoxicity tests against human tumors cell lines were carried out at the Cell Culture Laboratory, Pharmaceutical College, Jilin University, using modified protocols for MCF-7 
(breast cancer), SK-MEL-2 (skin melanoma) and COR-L23 (lung carcinoma), the normal cells were used as control [12]. Generally, $5 \times 10^{3} / \mathrm{mL}$ cells were placed in a 24 -well plate and treated with compound 1. The plate was incubated at $37{ }^{\circ} \mathrm{C}$ for 5 days. Then the medium was removed from the 24-well plate, and 10\% ice-cold TCA (trichloroacetic acid, $1 \mathrm{~mL}$ ) was added. The plate was kept at $4{ }^{\circ} \mathrm{C}$ for two hours after which was washed four times with cold water, then stained with SRB (Sulforhodamine B, Sigma St. Louis, MO, USA). After washing with 1\% acetic acid, the bound dye was solubilized with Tris base A (Sigma) and $100 \mu \mathrm{L}$ of each sample were transferred into a 96-well plate, and then read at $492 \mathrm{~nm}$.

\section{Acknowledgements}

This work was supported by the grant from National Natural Science Foundation of China (30971885), Major Program of Transgenic Species Development of Ministry of Agriculture of China (2009ZX08009-062B) and Key Projects in the National Science \& Technology Pillar Program during the Eleventh Five-Year Plan Period (2009BADB3B05).

\section{References and Notes}

1. Evans, R. The steroid and thyroid hormone receptor superfamily. Science 1988, 240, 889-895.

2. Csermely, P.; Schnaider, T.; Soti, C.; Prohászka, Z.; Nardai, G. The 90-kDa molecular chaperone family: structure, function, and clinical applications. A comprehensive review. Pharmacol. Ther. 1998, 79, 129-168.

3. Czar, M.; Galigniana, M.; Silverstein, A.; Pratt, W. Geldanamycin, a heat shock protein 90binding benzoquinone ansamycin, inhibits steroid-dependent translocation of the glucocorticoid receptor from the cytoplasm to the nucleus. Biochemistry 1997, 36, 7776-7785.

4. Stebbins, C.; Russo, A.; Schneider, C.; Rosen, N.; Hartl, F.; Pavletich, N. Crystal structure of an hsp90-geldanamycin complex: targeting of a protein chaperone by an antitumor agent. Cell 1997, 89, 239-250.

5. Patel, K.; Piagentini, M.; Rascher, A.; Tian, Z.; Buchanan, G.; Regentin, R.; Hu, Z.; Hutchinson, C.; McDaniel, R. Engineered biosynthesis of geldanamycin analogs for Hsp90 Inhibition. Chem. Biol. 2004, 11, 1625-1633.

6. Hu, Z.; Liu, Y.; Tian, Z.; Ma, W.; Starks, C.; Regentin, R.; Licari, P.; Myles, D.; Hutchinson, C. Isolation and characterization of novel geldanamycin analogues. J. Antibiot. 2004, 57, 421-428.

7. Rascher, A.; Hu, Z.; Buchanan, G.; Reid, R.; Hutchinson, C. Insights into the biosynthesis of the benzoquinone ansamycins geldanamycin and herbimycin, obtained by gene sequencing and disruption. Appl. Environ. Microbiol. 2005, 71, 4862-4871.

8. Vetcher, L.; Tian, Z.; McDaniel, R.; Rascher, A.; Revill, W.; Hutchinson, C.; Hu, Z. Rapid engineering of the geldanamycin biosynthesis pathway by Red/ET recombination and gene complementation. Appl. Environ. Microbiol. 2005, 71, 1829-1835.

9. Hong, Y.; Lee, D.; Kim, W.; Jeong, J.; Kim, C.; Sohng, J.; Lee, J.; Paik, S.; Lee, J. Inactivation of the carbamoyltransferase gene refines post-polyketide synthase modification steps in the biosynthesis of the antitumor agent geldanamycin. J. Am. Chem. Soc., 2004, 126, 11142-11143. 
10. Ruan, C.; Zhang, H.; Zhang, L.; Liu, Z.; Sun, G.; Lei, J.; Qin, Y.; Zheng, Y.; Li, X.; Pan, H. Biotransformation of ginsenoside $\mathrm{Rf}$ to $\mathrm{Rh}_{1}$ by recombinant $\beta$-Glucosidase. Molecules 2009, 14 , 2043-2048.

11. Deboer, C.; Meulman, P.; Wnuk, R.; Peterson, C. Geldanamycin, a new antibiotic. J. Antibiotics 1970, 23, 442-447.

12. Baruch, B.; Lina W.; Einat, B.; Jardena, N.; Jacob, S.; Haim, G.; Eyal, F. Variable cytotoxicity of amifostine in malignant and non-malignant cell lines. Oncol. Rep. 2003, 10, 1609-1613.

Sample Availability: Samples are available from the authors (contact drxiang@hotmail.com).

(C) 2010 by the authors; licensee Molecular Diversity Preservation International, Basel, Switzerland. This article is an open-access article distributed under the terms and conditions of the Creative Commons Attribution license (http://creativecommons.org/licenses/by/3.0/). 